\title{
The risk assessment of ships manoeuvring on the waterways based on generalised simulation data
}

\author{
L. Gucma \\ Maritime University of Szczecin, Poland
}

\begin{abstract}
This paper presents a new probabilistic method of navigational risk assessment. The method is based on real time simulation results. It is a complex method which consists of three separate methods: real time ship manoeuvring simulations, Monte Carlo method and analytical model of accident consequences. It allows for extending the simulation results over the waterway lifetime and all possible meteorological conditions. The main advantage over the fast time simulations is elimination of inaccurate human navigator models. The navigator behaviour is propagated to this method by means of several statistical distributions.
\end{abstract}

\section{Introduction}

The growing complexity in today's navigational safety research sets strong demands to the scientists. The real time simulation method, assumed as the most advanced and accurate method nowadays [2], is not sufficient in several aspects of risk analysis, especially in extending the researches for longer time period and the detailed consequences analysis. The paper presents new method which is based on real time simulation and extends the results achieved in real time simulation into the future. Two approaches are used. The first of them based on Fourier transformations was originally proposed by Quy et al [4] and the second one based on a pure probabilistic approach is used by the author $[1,3]$.

The detailed research procedure is presented on Figure 1. The first stage real time simulations are used to determine the probability density functions of ship position during passage along the analysed waterway and the distributions 
of ship speed and courses. During real time simulations, human operators are used and thus the method takes into account human factor.

Second step - the Monte Carlo method is used for extending the results over the waterway lifetime and possible meteorological conditions during its operation. It applies the previously determined distributions of ships positions that allow the assessment of probabilities of collision with water area elements (embankments, quays, fixed structures etc.). The most important factor in the presented method is the possibility of taking into account the critical technical failures during ship passage. The model calculates it by the distributions and intensities of such events and applies the analytical models of ship behaviour after the technical failure. A very important factor in such models is the correlation between following ships positions. The calculation of ships collision load and energy that are necessary for further consequence analysis is made on the basis of distribution of ship speed obtained in the real time simulations.

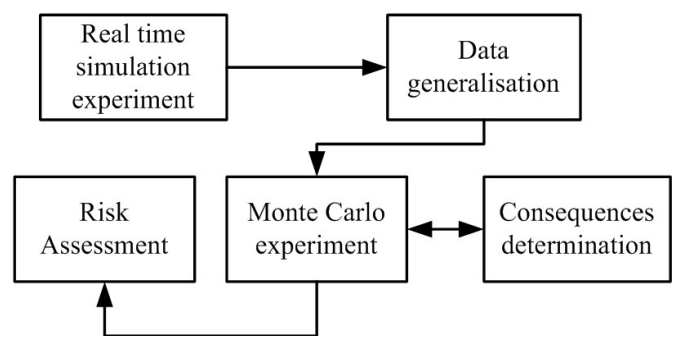

Figure 1: General diagram of presented approach.

\section{Problems of simulation data generalization}

The most important aspect that should be considered is real time simulation data generalisation. This paper presents most important topics that should be taken into account during such model development and finally two different models are presented.

\subsection{Real time simulation method}

Real time simulations are conducted with use of a computer model of the ship and environment in simulated meteorological conditions. This research is rather expensive and time consuming so it should be reduced to the minimum that guarantees statistical significance to achieve results. Real human navigators were employed as ships operators. Such procedure avoids describing humans by a mathematical model which is beyond today's possibilities. The human influence is therefore propagated through the presented model and described by means of estimated statistical distributions. The most important distributions applied in the presented case study are: 1). distribution of ships positions (centre of gravity and extreme starboard and port points of ships waterline) in respect to the centre of the waterway, 2). distribution of ships courses, 3). distribution of ships speed (horizontal, vertical and angular). 


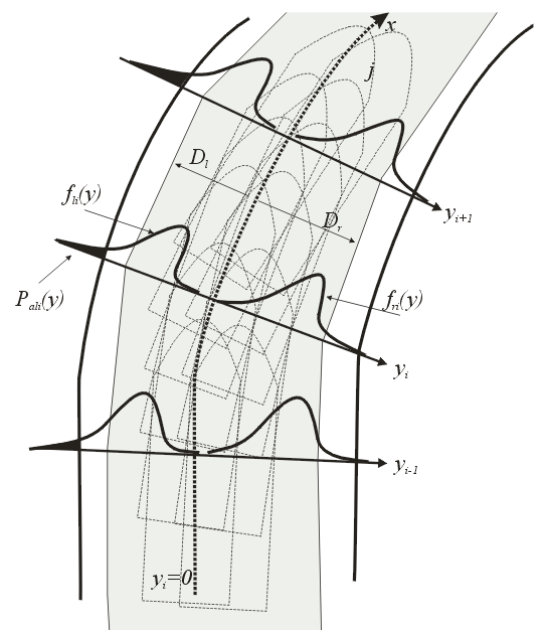

Figure 2: Graphical explanation of safety water area and probability of collision with the embankments assessment.

Based on distributions of ship positions achieved in such a way (Fig. 2) the probability of accident due to safe waterway exit can be evaluated as follows:

$$
P_{a}=\int_{d_{\max }}^{+\infty} f(y) d y
$$

where $f(y)=$ density function of ship extreme positions; $d_{\max }=$ distance from the waterway centre to its boarder.

\subsection{Example of simulation results - single section analysis}

Simulations are usually conducted in series, performed in different meteorological conditions, each consisting of several trials. In the presented research the real time simulations were performed with use of a 196 meter length, 28 meter breadth computer model of a single propeller tanker. The simulation research consists of 5 series in different wind and current conditions.

Usually the distances of ships points from the centre of the waterway can be well described by a normal distribution. The example of such a distribution for one of the simulation series is presented in Figure 3.

Distribution of ships courses is strongly correlated with ships positions referred to the middle of the waterway. It can be straightforwardly explained: the more the ship is away from the centre of the waterway the more the navigator changes the course to come back to the desired track. This phenomenon can be seen on Figure 4. To include such an observable fact into the model it is proposed to use a simply linear regression model. The course could be calculated by distribution of the distance from the middle of the waterway by the regression formula (Fig. 5) with use of previously calculated normally distributed regression error. 
414 Safety and Security Engineering II

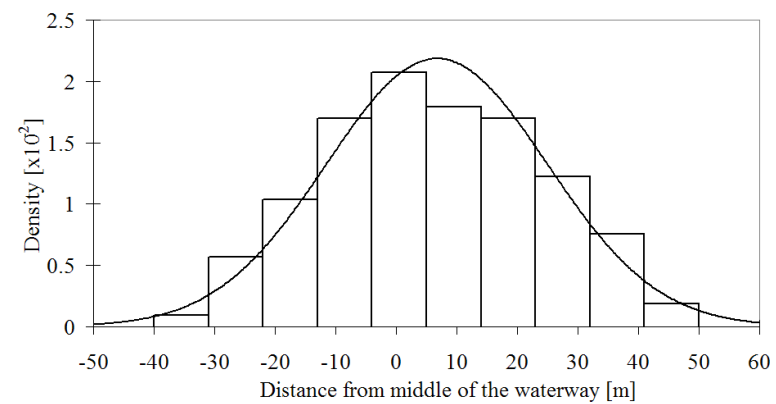

Figure 3: Histogram of the ship centre of gravity distances from the waterway centre fitted to normal distribution (single section).

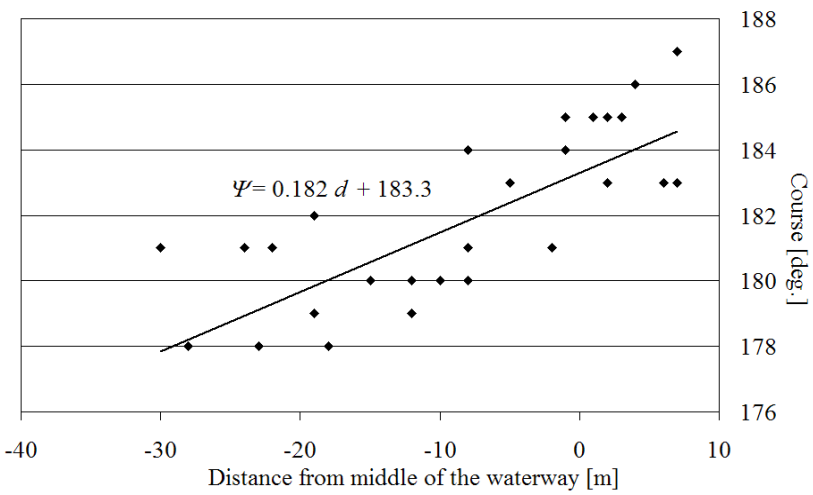

Figure 4: Linear correlation between distance from the waterway centre and ships course for one investigated simulation trial (single section).

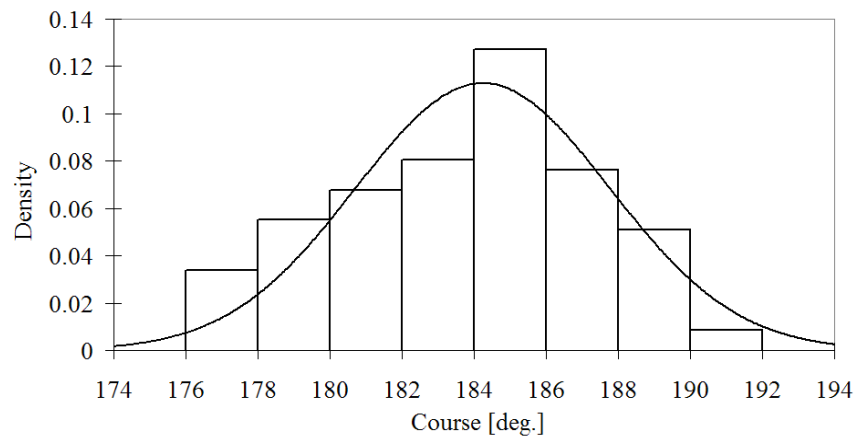

Figure 5: Histogram of courses fitted to normal distribution (single section).

The histogram of ships courses is presented in Figure 5. Although little skewness is observed due to bending of the waterway, the statistical tests of normality are positively verified at the specified significance level. 


\subsection{Real time simulation results: the whole ship's passage}

The single section analysis is not useful in many kinds of risk analyses especially when detailed consequence analysis should be carried out. The most important factor is dependence of position and heading in following sections. The final passages of ships in simulations (1 series of 30 passages) are presented in Fig. 6.

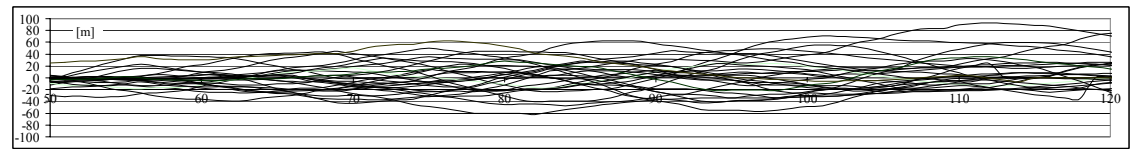

Figure 6: Recorded real time tracks of ship's centre of gravity in real time simulation passages.

\section{Probabilistic model of ships passage}

The general idea of real time simulation data generalisation is presented in Figure 7. It should be noted that ship movement is a very complex and dependent stochastic process. Two methods of modelling such a process have been presented in further parts of this paper.

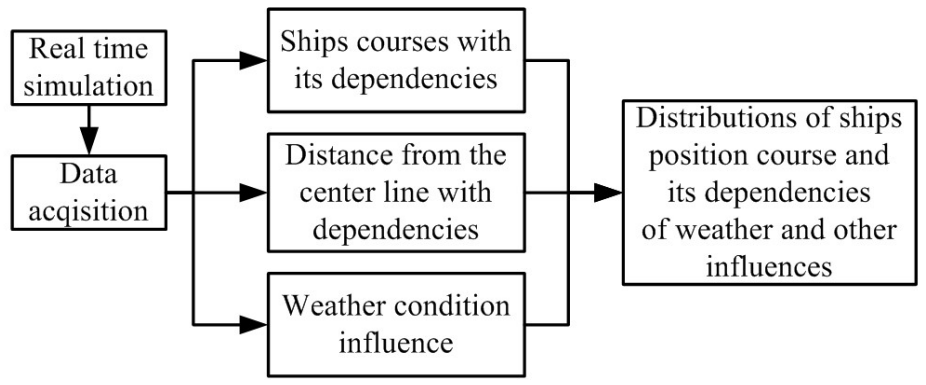

Figure 7: Procedure of data collection in presented method.

The first model is based on a simplified Markow model with the assumption that the next ship position is a function of only one past position: $\left(x_{(i+l)}\right.$, $\left.y_{(i+l)}\right)=f\left(x_{i}, y_{i}\right)$ and is generated with use of a simple linear regression model in several intervals. Additionally the distribution of consecutive minimal and maximal differences of distance from the centre of the waterway $\Delta y$, where $\Delta y_{i}=\left(y_{\text {imax }}-y_{\text {imin }}\right)$ is applied. This distribution is used for generation of the next point of maximal or minimal distance to the centre of the waterway (Fig. 8).

To build a second, more advanced model, several conditional distributions were used. The $\Delta x$ distribution, where $\Delta x_{i}=\left(x_{\text {imax }}-x_{\text {imin }}\right)$ and $\Delta y$ distribution, where $\Delta y_{i}=\left(y_{\text {imax }}-y_{\text {imin }}\right)$ were used. These two distributions describe maximal and minimal points of the ship track. By means of generated points the mean $\Delta y_{i} / \Delta x_{i}$ slope is obtained. In a further step the next position $\left(x_{k}, y_{k}\right)$ of the ship is generated with use of conditional distributions $\left(x_{k}-x_{k-1}\right)=f\left(x_{i m i n}-x_{k-1}\right)$ and $\left(y_{k}-y_{k-}\right.$ 
$\left.{ }_{1}\right)=f\left(y_{\text {imin }}-y_{k-1}\right)$ (Fig. 8). These distribution are responsible for changes in slope at a given point in comparison to the mean slope between $\left(x_{\text {imax }}, y_{\text {imax }}\right)$ and $\left(x_{\text {imin }}\right.$, $y_{\text {imin }}$ ) (Fig.8).

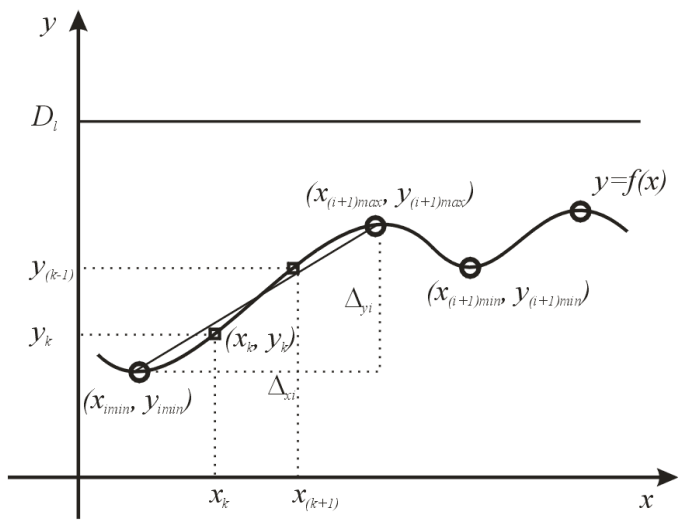

Figure 8: Definition of variables and distributions used in the paper.

\section{Results}

Figure 7 presents results obtained by the first model. Some unrealistic increases of position in the $Y$-axis could be observed mostly due to high changes of the distance to the middle of the waterway in consecutive points.

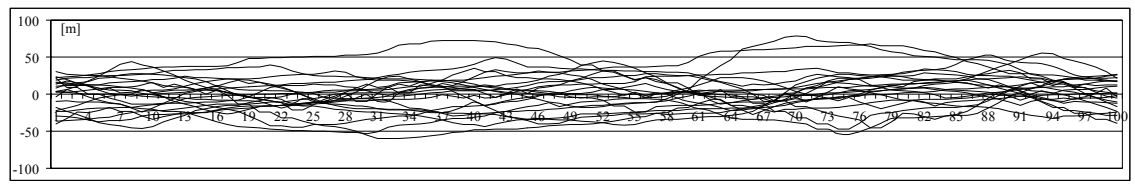

Figure 9: Statistically generated tracks of ships in several passages (model 1).

The results of the second model are presented in Figure 10. A behaviour more similar to reality behaviour of the model is observed. This model still needs some adjustments especially in some aspects of the observed roughness in ship tracks.

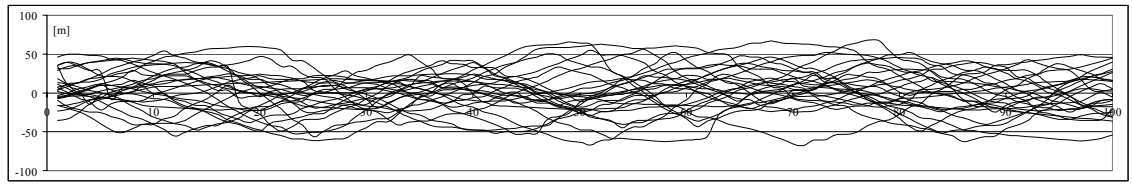

Figure 10: Statistically generated series of ships tracks in several passages (model 2). 
In a further step the statistical validation of two presented Monte Carlo simulation models have been carried out. The average performance of two presented models in comparison to real time simulation results have been carried out with use of all generated points $\left(x_{i}, y_{i}\right)$ (Fig. 11). The second model gives a much better approximation than the first one. Another important area of verification could be the validation with use of an extreme value distribution of ships extreme points during passage (tail areas of the distributions presented in Figure 11).

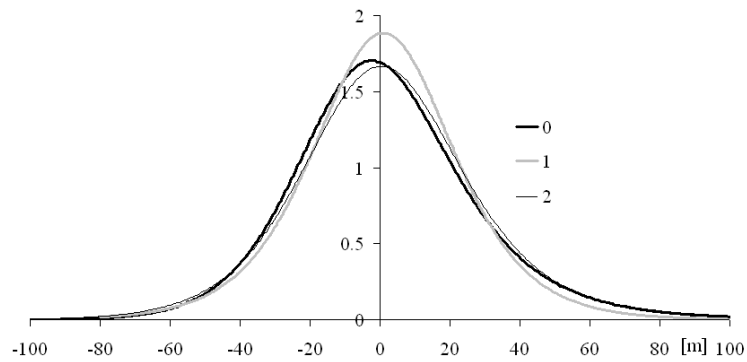

Figure 11: Comparison of the distribution of all simulated ship's positions in real time simulation (0), first model (1) and the second model (2).

\section{Conclusions}

The paper presents a novel method that could be used for more accurate navigational risk analysis in restricted areas. The method, due to its complexity, can be applied for all kinds of waterways, port entrances, basins, bridges and ships manoeuvring in any conditions. The most expensive part of it related to real time ship manoeuvring simulations is reduced to necessary minimum. The results obtained with the presented method are usually in the form of distributions (for example: ship load distribution on the bridge pier) usually for long time periods of waterway operation (Fig.12).

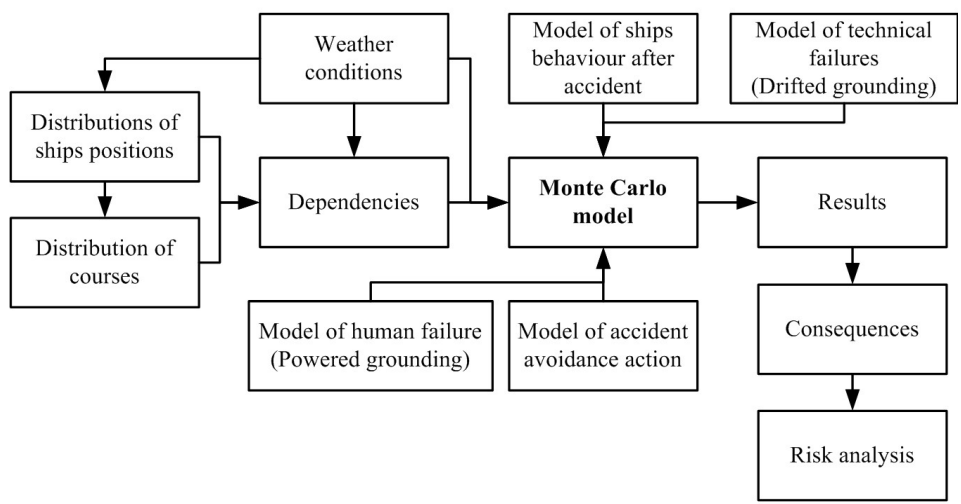

Figure 12: Final method of navigational risk assessment for restricted waterways. 
Additionally the method could be useful for optimal design of the waterway elements that are exposed to the possibility of ship collision. Further steps could concentrate on improvement of the Monte Carlo model including more distributions in it, together with more complex models of ship load determination.

\section{References}

[1] Courbach M., Gucma L., Proske D. Complex method of bridge safety assessment in respect to ship collision. $2^{\text {nd }}$ International Congress of Seas and Oceans, Szczecin 2005.

[2] Gucma L. Risk models of ship collision with fixed object. (in polish), Akademia Morska, Szczecin, 2005.

[3] Gucma L. Methods for bridge safety assessments with respect to ship collisions. K. Kolowrocki (edt.) Safety and Reliability, Balkema. Rotterdam 2005.

[4] Quy N.M., Vrijling J.K., van Gelder P.H.A.J.M., Groenveld R., Methods to assess safety criteria of approach channels with respect to the acceptability of ship grounding risks. Proc. of the 6th International Symposium of Navigation, Maritime University Gdynia, 2005. 